\title{
Sciendo
}

\section{Psychological obstacles to multiculturalism: how stereotypes and mechanisms of defence may cause adverse behaviours to multiculturalism.}

\section{Guido Amoretti}

Ph.D., Full professor in General Psychology, Department of Science of Education [DISFOR] University of Genoa - email: guido.amoretti@unige.it

\section{Doi: $10.2478 /$ gssfj-2018-0003}

\begin{abstract}
Migration flows are part of buman history. The process of globalization, if on the one hand it seems to favour the movement of buman beings, on the other hand it is creating the conditions for the recovery of migratory flows, especially within some areas of the world and, in part, directed towards advanced development countries. This creates problems of acceptance on the part of the host with respect to the customs and habits of the guest. Resistance to reception, used for political ends by populist parties, has deep roots that have to do with psychological and social factors: defence mechanisms, stereotypes and prejudices. The article stresses the importance of training in overcoming these obstacles to building a society that is first multicultural and then intercultural.
\end{abstract}

Keywords: defence mechanisms, stereotypes, prejudices, migration, multiculturalism

\section{Introduction}

The phenomenon of migration belongs to the history of humanity. Driven by the search for new territories rich in game, new lands to work, new sources of raw materials many of the peoples of antiquity have faced dangerous journeys to settle in new areas, often coming into conflict with people in those areas lived. After the industrial revolution, migration flows have been caused by the search for work and escape from poverty, but with the advent of globalisation, the movements have become much easier and more frequent, encouraging the creation of culturally homogeneous groups within culturally dissimilar contexts. The coexistence between the dominant culture and the other cultures is often problematic due to the difficulty of accepting customs and styles of life where the differences are frequently significant.

We do not intend to examine the anthropological and sociological causes which contribute to triggering xenophobic and discriminatory behaviours but to understand the psychological mechanisms that favour the recruitment of 
behaviours that hinder the affirmation of a multicultural attitude that is indispensable to the spread of interculturalism.

\section{Needs and motivations}

Psychological studies include among the motivations "affiliation", that is, the propensity of the human being, defined as "a social animal", to seek membership of a group. The evolution of our species has been characterized by the need of belonging to a group: from the first family units to tribes to come up to the nations the history of mankind is marked by successive and increasingly complex aggregations of individuals. Maslow (1970), in his theory of motivation, puts the need for affiliation in an intermediate position between the physiological needs and safety and those relating to self-esteem and self-actualization (Fig.1).

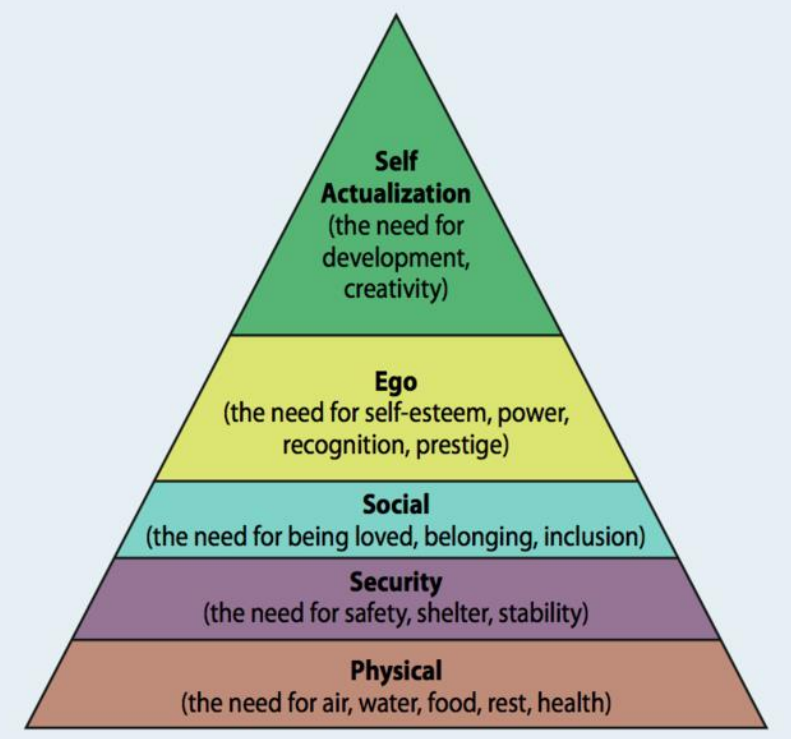

Fig.1 - Maslow's hierarchy of needs (Maslow, 1970).

Once satisfied basic needs and security, essential for the survival of the individuals, the social animals, such as man, tend to form groups with opportunistic purposes. The aggregations are based on affinity and/or common goals and tend to link members in an exclusive way: those who do not belong to the group or is a member of other groups is not immediately welcomed. The differences that exist between the different aggregations are used to identify members of one or the other group: clothing, expressions, language, cultural traits can change, even in an obvious way, from one group to another even when the groups belong to, for instance, larger aggregations.

It is a common experience in all Countries that, within the same Nation, coexist groups that are characterized by different habits and customs, both on a regional basis, both at a micro level. In Italy, for example, there are strong cultural and linguistic differences between different regions, in particular between those from 
the north and the south, which correspond to the attitudes and different rhythms of life. In the years of the economic boom, with the internal migration of labour from the agrarian south moved to the industrial north, the coexistence of these "diversity" has been very difficult, resulting often in racist behaviour which opposed, for a long time, the process of inclusion. During those years, in some areas of Northern Italy, it was not uncommon to come across signs such as "don't rent to southern". At the base of these events to be discriminatory, was the stereotype, which attributed to the "southern" poor hygiene, lack of attention to the things of others and of the community: those who owned apartments are protected from rent the premises to persons whom they feared would damage the property. Stereotypes related to groups coming from different geographical areas are widespread throughout the world, just think of the thousands of jokes and jokes that have been circulating on Italians, Poles or Jews. But there are groups that amplify the need of belonging, emphasizing their specificity as opposed to those of others, even to the micro level (the Districts of Siena, the youth gangs, etc). Every year in Tuscany, in Siena, the inhabitants of the various districts (Contrade) challenge each other for the conquest of the Palio, a long piece of precious fabric, making a race in which horses are ridden without a saddle along the ring of the main square. The sense of belonging to their own Contrada is so strong that the" locals" come to finance the participation in the race by pouring money and/or working free of charge to set up the event, and frequently the discussions between advocates of different districts are transformed into violent fights motion (Paradis 2014). A further example of a stereotype linked to membership of a group, less folk and more relevant in social terms, is represented by the phenomenon of youth gangs. Also, in this case, the membership of a group determines language, attitudes and clothing, all elements that facilitate the recognition of those who do not belong to the group, and most of the times, is identified as a foreign body, as belonging to another band, and then to fight. But the same process of identification is done to the contrary by those who do not belong to the world of the band and blame to it constantly acts of violence, illegal behaviour, etc., (Queirolo Palmas, 2009). Need to belong leads then to the stigmatisation of the differences.

\section{From defence mechanisms to stereotypes}

The arrival of individuals who belong to other groups is viewed with suspicion, so much the greater are the differences and the greater the conviction that the newcomers might become competitors as regard to the work. And how much more obvious are the differences in, how much more easily the "strangers" will be identified and will be evaluated on the basis of the current stereotypes.

But what determines the stigmatisation of the differences and why this is the case in any situation in which there are comparisons with the "diversity" (different ethnicity, different language, different religion, different abilities or disabilities)? At 
the base, we find the fear of the unknown, fear that what we don't know represents some danger. The apprehension in respect of what is unknown, is a legacy of the evolution of our species since the time of the capture signals of a possible safety danger, meant to alert the body and prepare for an action, no matter what, the greatest efficacy would be determined by the speed with which it was to be performed. But soon this undifferentiated fear is realized first of all with respect to the presence on the territory of persons not belonging to the original group, with the consequent need to share the space; then the "intruder" is perceived as a possible competitor with regard to the available resources, employment opportunities, availability of services, and so on.

To emphasize their belonging to a group becomes, therefore, an act of defence from "the other", someone who you don't know, if not superficially or by hearsay, and that is not meant to know directly, as if the activation of any relationship with the "other" could trigger a process of humanization, and so prevent the attribution of negative characteristics, which are indispensable to the birth of stereotypes that generate distrust and hostility. The image of the migrant that the welcoming population creates, is the results of the sum of many stereotypes, which, once generalized, define any belonging to a different group in terms of the distance from the characteristics of the group that judges.

The lack of direct knowledge of the characteristics of the "other" allows for the sedimentation of negative stereotypes, serve to increase the hostility towards those who are considered a danger to their way of life. This process of dehumanisation of "the other", a well-known phenomenon of mass psychology that might be useful for clinical approaches (Anagnostopoulos et al., 2008), is knowingly and deliberately fostered and fuelled by proponents of a conflict, both intra-national and international.

The political movements commonly referred to as "populist" should their current success, undeniable and transcontinental, to have been able to emphasize the fears towards everything that is different from the national identity, speaking to the emotional part, atavistic and not easily controllable, of the people. The emotions take over to the point that, in a country like Italy, we forget that 4.9 million compatriots live and work abroad (A.A.V.V., 2017) (Fig. 2), and may suffer the same forms of discrimination, segregation and racism. 


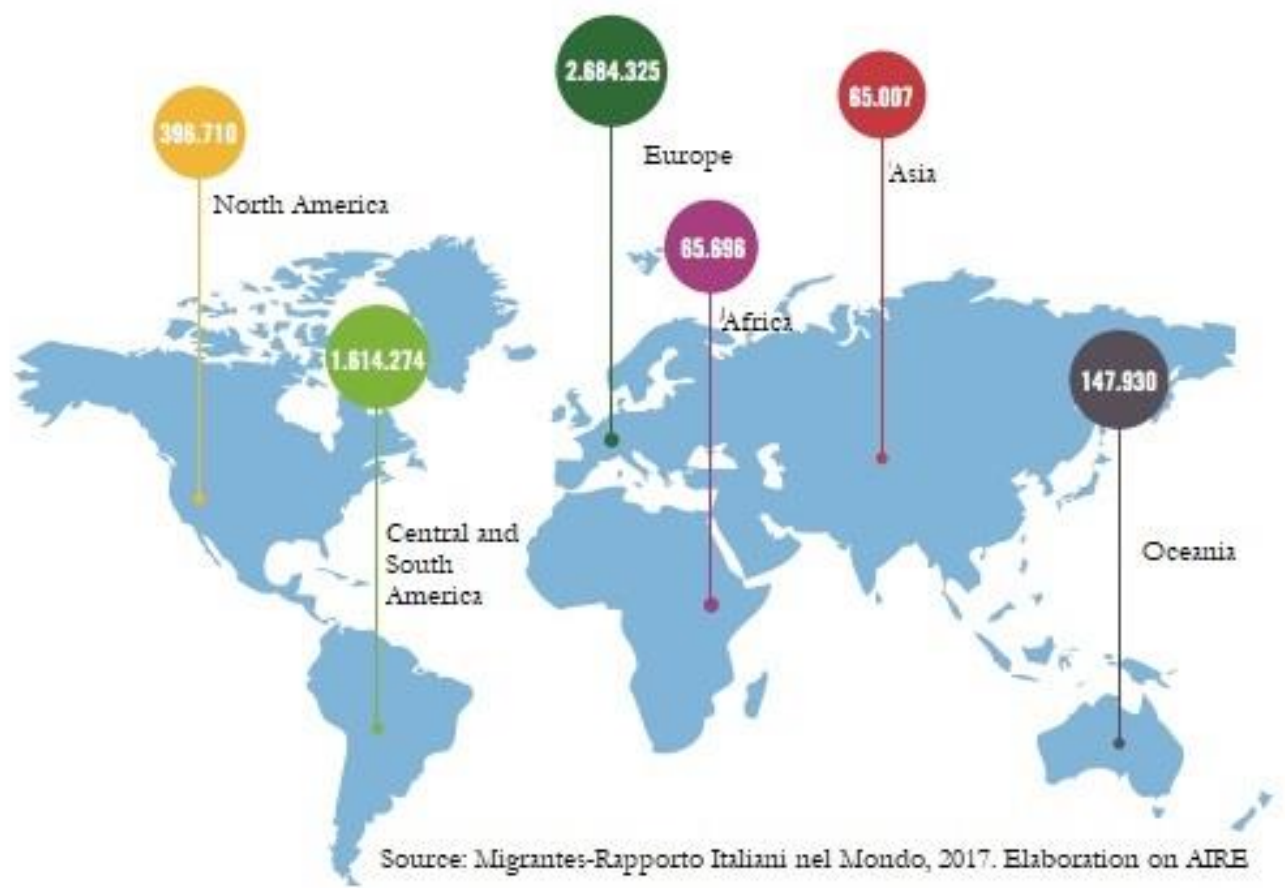

Fig.2 - Italian People who live and work abroad (A.A.V.V., 2017).

The key to a multicultural coexistence, real and not a facade, it's the knowledge of one another's differences, not to adhere to different cultural models as to understand the nature, the historical and social reasons, to accept the life without afraid of intrusiveness. Ignorance generates suspicion, the mistrust that prevents the knowledge: this vicious circle, when it's established, tends to cancel the possibility that different worlds meet each other. Get to know the "other" means not passively accept the circulating stereotypes and those proposed by those who have the interest to attract the attention of more about the false causes of the deterioration in the perceived quality of life. But to succeed in this intent it's necessary to possess the minimum cultural tools to be able to analyse the interpretations that are proposed and be able to read the otherness in an unconventional way, assuming that it's an opportunity and not a constraint.

From this point of view, the training, formal and informal, is fundamental in order to try to defeat the innate fear towards novelty and differences. The ability to assume an attitude not defensive must be cultivated from the earliest educational moments: the acceptance of the other as well as the ability to overcome the easy stereotypes about those who do not belong to our "tribe", are the result of an 
educational process that puts at the centre the theme of inclusion. The term inclusion represents the evolution of the terms insertion and integration that are used to indicate the progressive change in the way of conceiving the presence of disabled children in school classes. In Italy this change has started since 1977 with the abolition of special schools and the inclusion of people with disabilities in the classes: initially, it was a simple addition to the group class (insertion), then we worked on the mutual exchange between people (integration) and, finally, was developed the concept of inclusion as a process, a framework within which all of the conditions can be valued, respected and given opportunities at school. Although initially related to the need to enable synergies between pupils with disabilities and pupils without disabilities, the concepts of insertion, integration and inclusion have proved to be useful to deal with other special educational needs, such as those determined by the coexistence in the same class of students from different cultures and of different native speakers, and they have been used, by analogy, to describe different ways to deal with the multiculturalism resulting from migratory processes that have characterized the last twenty years. In Countries such as Italy, inclusion was and is an integral part of training and we can say that it's now part of the DNA of the Italian school system. However, this educational success is such almost exclusively as regard to the disability in respect of which parents and children have developed inclusive attitudes and abandoned the temptation of rejection and isolation.

In fact, if the process of inclusion of disabled people has now become a common cultural heritage, the situation is still unbalanced with respect to the acceptance of "foreign", the carrier of other cultures and/or religions, even in the case of immigrants of second or third generation, so born in the host Countries. The positive effect associated to the diffusion of multicultural classes may be negated by the increasing prevalence of stereotypes about immigrant conveyed by the media and often made their own by their parents, whose influence on the attitudes of the children is superior to that of the educational system because of the natural processes of children/parents identification.

The parents, with the intention of protecting their children, can transmit their own fears about someone who is perceived as "different" by increasing those defence mechanisms towards those who don't know, that the daily interaction in a classroom between children of different cultures/religions should have refused. It is not a coincidence that the more items switched on contrary to the presence and arrival of immigrants come mainly from middle-low economical people, those who see immigrants as competitors in the acquisition of resources, but also those least equipped from a cultural point of view to analyse the information, and the stereotypes conveyed by media and by the various populisms that in this historical moment are present in several Countries of destination and/or transit of migration flows. 


\section{The Italian situation}

The worrying aspect, with respect to the situation in Italy, is the observation of a clear reduction in interest, on the part of the young population, for training processes that are not specifically aimed at achieving employment. Educational institutions struggle to carry out the task of developing critical thinking skills, the curiosity to know and understand the world, the mental habit of not being satisfied with the first explanation, of going beyond the news conveyed by the media. A large part of the Italian population tends to use information in a superficial way, reading only the titles of the news that are often partial or misleading with respect to the content of the article. Moreover, the influence of positivism seems to have produced only a great confidence in the numerical data and not also the need to verify the source, the quality and the correctness with which it was analysed. Statistics is probabilistic science and the same data can be interpreted in different ways. Let us take the relationship between crime rates and immigration as an example. The economic newspaper Sole24ore published an article, commenting on the results of a statistical survey on the relationship between crime and immigrants, entitled "Crimes of foreigners, the alert of the Viminale". The text highlighted, on the one hand, the high number of complaints against foreigners in relation to their numerical consistency, and, on the other, the decrease in crimes committed by immigrants (Ludovico, 2017). Of the two data, one supporting the perception of a lack of security, the other indicative of the effectiveness of immigration control policies in increasing security, only the first emerges from the title of the article. The same research was used to demonstrate how immigrants are involved in criminal activities 6 times more than Italians (Cartaldo, 2017) and to highlight how the high crime rate was attributable to irregular immigrants while legal immigrants commit crimes as much as Italians (Misculin, 2018). The first article blasted on prejudice reinforcing the equation immigrant=criminal, the second introduced distinctions, warned against generalisations that favour prejudice and appreciated the policy of the Gentiloni government and its Minister of the Interior, Minniti, aimed at reception but also at the fight against irregular immigration.

But how many of the readers of the various newspapers were able to go beyond the title or even beyond the statements of the journalist trying to see if the comment was really supported by the data? Surely not many if we consider that only $43.9 \%$ of the Italian population over 6 years of age reads the newspaper at least once a week. On the other hand, $86.7 \%$ of people over the age of three watch television every day: very young and elderly people are particularly diligent in following television programmes with values close to $96 \%$, while only $12 \%$ of those under 17 read a newspaper (ISTAT, 2017). The increasing use of Internet ( $92 \%$ of young people between 15 and 24 years surf daily) facilitates the circulation of information and opinions that, being mostly uncontrolled, end up attributing

1 Viminale is the popular name for the Italian Ministry of Interior 
absolute truth value to points of view based more on personal prejudices and beliefs than on a careful reading of reality.

The greater propensity to use TV and Internet compared to reading newspapers indicates a tendency to cognitive laziness, to the use of passive rather than active modes of learning: it is less demanding to listen to news on TV or read its summary on the Internet on a social network than to deal with the printed press. This phenomenon produces a forced selection of the information content of the news that is reduced to the essential, isolating it from the context and introducing distortions. Added to this is the fact that those who do not have the necessary skills and the appropriate curiosity will choose the information congruent with their thinking not considering those that could question their opinions. This mechanism of seeking confirmations and closing to what appears dissonant is well known by those who provide the news: information, understood as the search for and dissemination of information reported as faithfully as possible and freely, has become first an instrument of orientation of cultural and political attitudes of the reader and now a source of support for pre-existing opinions. The world of information seems largely interested in providing the news from a point of view appreciated by its readers, emphasizing the aspects more synergistic to their interests or their moods, without worrying about offering elements for reflection. Faced with a communicative situation like the one described above, the only way to invert the tendency to homologation, to the alignment of opinions to current thinking, is to develop critical thinking in the younger generations stimulating in them the desire to go beyond the surface of the news conveyed by the media.

In order for multiculturalism to assert itself, with its logic of tolerance, acceptance and maintenance of different cultural identities, it is, therefore, necessary to develop an educational system that places the theme of inclusion at the centre of all the "diversities" that can be found in a modern and globalized society. Only in this way will it be possible to overcome the strength of the defence mechanisms, unmask the most reactionary stereotypes and set as a possible first goal multiculturality. In order to reach interculturality, the achievement of which is currently unlikely, it is, in fact, necessary to fully internalize multiculturalism, i.e. the acceptance of other cultures, before reaching their sharing without any culture losing its identity. The ambitious and difficult objective cannot be achieved through legislative decrees but only through sharing, overcoming stereotypes and abandoning the defence mechanisms that lead people not to accept those belonging to a different group in terms of language, race or customs (Anolli, 2011)

\section{References}

A.A. V.V. (2017). Rapporto Italiani nel Mondo 2017, Roma, Fondazione Migrantes.

Anagnostopoulos K., Germano F., Tumiati M.C. (2008). L' approccio multiculturale. Interventi in psicoterapia, counseling e coaching, Sovera Edizioni, Roma.

Anolli L. (2011). La sfida della mente multiculturale. Nuove forme di convivenza, Cortina, Milano. 
Cartaldo C. (2017): Immigrati, la verità nei numeri: "Crimini 6 volte più di italiani", Il Giornale, 2909-2017, [Online] Available http://www.ilgiornale.it/news/cronache/immigrati-verit-nei-numericrimini-6-volte-pi-italiani-1447414.html
ISTAT
(2017).
Annuario
Statistico
Italiano
2017
[Online] Available:

https://www.istat.it/it/archivio/213021

Ludovico M. (2017). Reati di stranieri, l'allerta del Viminale, Sole 24 ore, 29-09-2017 [Online] Available:http://www.ilsole24ore.com/art/notizie/2017-09-28/reati-stranieri-1-allerta-viminale091713.shtml?uuid=AEHr3naC\&refresh_ce=1

Maslow A. (1970). Motivation and Personality (2nd ed.), Harper and Row, New York.

Misculin L. (2018). Che rapporto c’è fra immigrazione e criminalità, 05-02-2018 [Online] Available https://www.ilpost.it/2018/02/05/rapporto-immigrazione-criminalita/

Paradis T.W. (2014). Living the Palio: A Story of Community and Public Life in Siena, Bloomington, iUniverse Inc.

Queirolo Palmas L.(a cura di) (2009). Dentro le gang. Giovani, migranti e nuovi spazi sociali, Verona, Ombre corte. 